\title{
PENGARUH KUALIFIKASI HASIL SELEKSI TERHADAP PRODUKTIVITAS KERJA KARYAWAN DI GRAND ROCKY HOTEL BUKITTINGGI
}

\author{
Feri Ferdian ${ }^{1}$, Ira Meirina Chair ${ }^{1}$,Fitri Afriana ${ }^{2}$, \\ ${ }^{1}$ Dosen Program Studi D4 Manajemen Perhotelan FPP UNP \\ ${ }^{2}$ Alumni Program Studi D4 Manajemen Perhotelan FPP UNP \\ Email:feri_ferdian@fpp.unp.ac.id
}

\begin{abstract}
The purpose of this research is to examine the influence between the qualification of selection toward work productivity employee in Grand Rocky Hotel Bukittinggi. The Type of research is clausal assosiative. The sampling technique is probability sampling by using proportionate stratified random sampling. Sample in this research are amounted to 53 people. Data collecting using questionnaires based on likert scale that has been tested of validity and reliability. Based on the result of there research concluded that in general about qualification of selection in Grand Rocky Hotel Bukittinggi is als good 38,62 \%. Work productivity employee in Grand Rocky Hotel Bukittinggi is also good 66,7 \%. The result also indicate that are significant influence between qualification of selection and work productivity in Grand Rocky Hotel Bukittinggi is 51,2\% and 48,8\% another factor on a 0,000 < 0,05 significant.
\end{abstract}

\section{Key Word: Qualification of Selection and Work Productivity}

\section{PENDAHULUAN}

Pada era globalisasi ini industri perhotelan berkembang sangat pesat, indsutri perhotelan merupakan industri yang menawarkan perpaduan antara produk dan jasa. Banyak pengusaha bersaing dalam mendirikan hotel di berbagai daerah yang mereka anggap memiliki prospek bagus dalam bisnis hotel untuk kedepannya. Banyaknya minat pengusaha menimbulkan persaingan yang sangat ketat pada industri perhotelan, hal ini menuntut pengusaha harus cermat dalam memilih konsep perusahaan mereka. Untuk menghasilkan kualitas pelayanan yang baik, maka manajemen sumber daya manusia hotel harus diperhatikan.

Menurut Priyono dan Marnis (2008:4) Manajemen Sumber Daya Manusia adalah pengakuan tentang pentingnya tenaga kerja organisasi sebagai sumber daya manusia yang sangat penting dan memberi kontribusi bagi tujuan- tujuan organisasi, serta penggunaan beberapa fungsi dan kegiatan untuk memastikan bahwa SDM tersebut digunakan secara efektif dan adil bagi kepentingan individu, organisasi maupun masyarakat. 
Sumber daya manusia yang berkualitas merupakan kekayaan (asset) yang tidak ternilai bagi suatu hotel. Industri perhotelan berusaha menyeleksi karyawan baru yang kompeten di bidangnya sehingga akan tercipta produktivitas kerja yang baik oleh individu tersebut. Menurut Ravianto dalam Bayu (2012), "Produktivitas kerja karyawan adalah sebagai suatu konsep yang menunjukkan adanya kaitan antara out put (hasil kerja) dengan waktu yang dibutuhkan untuk menghasilkan produk dari seseorang tenaga kerja yang sangat berkaitan dengan hasil kerja yang diperoleh terhadap waktu yang diperlukan untuk menghasilkannya".

$$
\text { Simmamora }
$$

(2004:

mengemukakan, "Untuk mengukur produktitivitas kerja diperlukan indikator sebagai berikut: 1) Kualitas Kerja, 2) Kuantitas Kerja, dan 3) Ketepatan Waktu". Untuk mendapatkan karyawan yang mempunyai produktivitas kerja yang baik dan tidak merugikan perusahaan, maka perusahaan tersebut harus menerapkan dan menjalankan kualifikasi seleksi dengan tepat sehingga akan mendapatkan hasil seleksi yang sesuai dengan kriteria yang diinginkan perusahaan/ hotel.menurut Bangun (2012: 159), "Seleksi adalah proses memilih calon karyawan yang memiliki kriteria sesuai dengan persyaratan pekerjaan, kegiatan seleksi dilakukan untuk mengurangi sebagian jumlah pelamar, sehingga diperoleh calon karyawan terbaik. Tanpa karyawan berkualitas sulit bagi perusahaan untuk mencapai keberhasilan”.

Jadi kualifikasi hasil seleksi adalah keputusan diterima/ di tolaknya pelamar yang telah menjalani serangkaian proses seleksi, pelamar yang di terima adalah pelamar yang memenuhi kasifikasi seleksi di bidang pengetahuan, keterampilan, kemampuan dan karakteristik lainnya yang diharapkan dapat memenuhi standar kerja suatu organisasi/ hotel.

Hasibuan dalam Kristanu (2013) mengemukakan ada 9 kualifikasi seleksi calon karyawan yaitu: “1) Keahlian, 2) Pengalaman Kerja, 3) Kesehatan, 4) Latar Belakang Pendidikan, 5) Umur, 6) Kerja Sama, 7) Kejujuran, 8) Inisiatif dan Kreatif, serta 9) Kedisiplinan”.

Grand Rocky Hotel Bukittiggi adalah Hotel Bintang Empat (****) yang berlokasi di kota Bukittinggi, Sumatera Barat tepatnya di Jalan Yos Sudarso No. 29 Benteng Bukittinggi, dengan arsitektur bangunan yang modern. Grand Rocky Hotel Bukittinggi juga 
memberikan pelayanan kepada tamu demi mencapai kepuasan tamu menginap.

Berdasarkan observasi awal peneliti saat melakukan Praktek Kerja Lapangan Industri pada tahun 2016 di Grand Rocky Hotel, peneliti menemukan tidak tercapainya standar jumlah hasil kerja oleh beberapa karyawan di dua department yaitu di departmen housekeeping dan sales marketing. Pada departmen house keeping seharusnya karyawan membersihkan 17 kamar dalam 1 hari, tetapi ada karyawan yang hanya bisa 14- 15 kamar dalam satu hari. Selanjutnya pada departmen sales marketing, para sales excecutive ditargetkan mendapat 20 event dalam 1 bulan, tetapi ada sales yang hanya bisa mendapat 15 event dalam 1 bulan.

Kualitas kerja karyawan housekeeping belum baik karena masih adanya complain tamu tentang kamar yang sangat kotor, pada saat tamu memasuki kamar mereka melihat meja kamar yang kotor dan berdebu, bau kamar yang menyengat dan gorden yang kotor. Hal ini menyebabkan ketidak nyamanan tamu dan merasa tidak betah menginap di Grand Rocky Hotel. Selanjutnya tamu juga mengeluh tentang kualitas kerja staff, seputar pelayanan staff dinilai tidak ramah saat melayani tamu, hal ini disebabkan karenan reception tidak memberikan senyum sambutan saat kedatangan tamu di meja reception. Selain itu acount receivable tidak tepat waktu menyelesaikan payment credit card dan city ledger. Pada awal bulan acount receivable melakukan payment credit card dan city ledger, dan ditargetkan menyelesaikan hal tersebut sebelum penerimaan service karyawan.

Untuk mendapatkan SDM yang bermutu, pihak hotel terutama HRD harus menerapkan klasifikasi seleksi dengan tepat. Pihak hotel belum melakukan penerimaan karyawan yang sesuai dengan job specification. Job Specification sudah disediakan sebelum seleksi dilaksanakan jadi interviewer pun sudah mengetahui kriteria apa saja yang dibutuhkan untuk pekerjaan yang akan di tempati. Tetapi banyak karyawan yang diterima tidak sesuai dengan job specification. Penempatan karyawan di Grand Rocky Hotel pun terbilang tidak sesuai dengan background pendidikan karyawan, karena masih ditemukan karyawan yang tamat tidak dari jurusan perhotelan.

Setelah calon karyawan diterima, saat melalukan training selama 3 bulan ada beberapa karyawan yang mengundurkan diri sebelum dikontrak. Alasannya adalah 


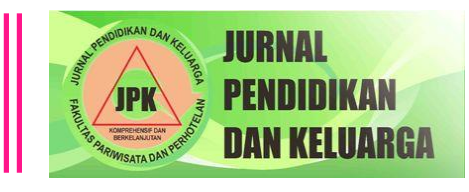

kurangnya pengetahuan mereka tentang bidang pekerjaan yang mereka tempati, karena pekerjaan tersebut tidak sesuai dengan keahlian dan background pendidikan yang mereka punya. Berdasarkan kenyataan yang ditemukan penulis di Grand Rocky Hotel Bukittinggi, maka penulis tertarik untuk meneliti dan mengangkat judul mengenai "Pengaruh Kualifikasi Hasil Seleksi Terhadap Produktivitas Kerja Karyawan di Grand Rocky Hotel Bukittinggi”.

\section{METODE PENELITIAN}

Jenis penelitian ini adalah penelitian asosiatif bentuk hubungan kausal. Populasi dalam penelitian ini adalah seluruh karyawan Grand Rocky Hotel Bukittinggi sebanyak 112 orang. Teknik pengambian sampel adalah probability sampling dengan menggunakan proportionate stratified random sampling. Jumlah sampel dalam penelitian ini adalah 53 orang.

Instrumen yang digunakan dalam penelitian ini adalah kuesioner (angket) yang disusun menurut skala likert yang telah teruji validitas dan reliabilitasnya. Teknik nalisis data penelitian ini menggunakan rumus penelitian rata-rata ideal $\left(\mu_{\mathrm{i}}\right)$, standar deviasi
$\left(\mathrm{Sd}_{\mathrm{i}}\right)$, dan diklasisifikasi menjadi 5 kategori Arikunto (2010) yaitu:

a. Kategori sangat baik: $\operatorname{Skor} \geq\left(\mu_{\mathrm{i}}+1,5 \mathrm{Sd}_{\mathrm{i}}\right)$

b. Kategori baik: $\left(\mu_{\mathrm{i}}+1,5 \mathrm{Sd}_{\mathrm{i}}\right) \geq \mathrm{Skor} \geq\left(\mu_{\mathrm{i}}+\right.$ $\left.0,5 \mathrm{Sd}_{\mathrm{i}}\right)$

c. Kategori cukup: $\left(\mu_{\mathrm{i}}+0,5 \mathrm{Sd}_{\mathrm{i}}\right) \geq \operatorname{Skor} \geq\left(\mu_{\mathrm{i}}\right.$ $\left.-0,5 \mathrm{Sd}_{\mathrm{i}}\right)$

d. Kategori buruk $:\left(\mu_{\mathrm{I}}-0,5 \mathrm{Sd}_{\mathrm{i}}\right) \geq$ Skor $\geq$ $\left(\mu_{\mathrm{i}}-1,5 \mathrm{Sd}_{\mathrm{i}}\right)$

e. Kategori sangat buruk: Skor: $<\left(\mu_{I}-1,5\right.$ $\left.\mathrm{Sd}_{\mathrm{i}}\right)$.

Untuk menentukan skor rata-rata ideal digunakan kurva normal sebagai berikut:

$\mu_{\mathrm{I}}=1 / 2$ (skor ideal maksimum + skor ideal minimum)

$\mathrm{Sd}_{\mathrm{i}}=1 / 6$ (Skor ideal maksimum - skor ideal minimum)

Dimana $: \mu_{\mathrm{I}}=$ skor rata-rata ideal dan $\mathrm{Sd}_{\mathrm{i}}=$ Simpangan baku

Selanjutnya dilakukan uji persyaratan analisis yaitu uji normalitas, uji homogenitas dan analisis regresi liniear sederhana yang digunakan untuk menghitung kadar pengaruh variabel X terhadap Y. 
HASIL PENELITIAN DAN

PEMBAHASAN

1. Analisis Kualifikasi Hasil Seleksi di Grand Rocky Hotel Bukittinggi

Berdasarkan hasil perhitungan statistik mengenai kualifikasi hasil seleksi di Grand Rocky Hotel Bukittinggi di peroleh rata-rata (mean) sebesar 52,66, skor terendah 39 dan skor tertinggi 66. Maka diperoleh gambaran kategori skor pada Tabel 1.

Tabel 1. Hasil Deskripsi Data Variabel Kualfikasi Hasil Seleksi $(\mathbf{X})$

\begin{tabular}{|l|l|c|c|}
\hline Kategori & $\begin{array}{l}\text { Rentang } \\
\text { Skor }\end{array}$ & Frekuensi & $\begin{array}{c}\text { Presentase } \\
(\%)\end{array}$ \\
\hline Sangat Baik & $\geq 60$ & 11 & 20,75 \\
\hline Baik & $\mathbf{5 0 - < 6 0}$ & $\mathbf{2 1}$ & $\mathbf{3 9 , 6 2}$ \\
\hline Cukup Baik & $40-<50$ & 20 & 37,73 \\
\hline Buruk & $30-<40$ & 1 & 1,9 \\
\hline Sangat & $<40$ & 0 & 0 \\
\hline Total & 53 & 100 \\
\hline
\end{tabular}

Sumber: Data Primer, 2017 (Diolah)

Berdasarkan Tabel 1 di atas dapat dikatakan bahwa Kualfikasi Hasil Seleksi di Grand Rocky Hotel Bukittinggi sebanyak $39,62 \%$ responden menyatakan baik, 37,73\% responden menyatakan cukup baik, 20,75\% responden menyatakan sangat baik, dan 1,9\% responden menyatakan buruk.

2. Analisis Produktivitas Kerja Karyawa di Grand Rocky Hotel Bukittingi.

Berdasarkan hasil perhitungan statistik mengenai produktivitas kerja karyawan di Grand Rocky Hotel Bukittinggi diperoleh rata-rata (mean) sebesar 38,43, skor terendah 20 dan skor tertinggi 60. Maka di peroleh gambaran kategori skor pada Tabel 2.

Tabel 2. Hasil Deskripsi DataVariabel Produktivitas Kerja (X)

\begin{tabular}{|l|l|l|l|}
\hline Kategori & $\begin{array}{l}\text { Rentang } \\
\text { Skor }\end{array}$ & Frekuensi & $\begin{array}{c}\text { Presentase } \\
(\%)\end{array}$ \\
\hline Sangat Baik & $\geq 48$ & 7 & 13,20 \\
\hline Baik & $\mathbf{4 0 - < 4 8}$ & $\mathbf{1 8}$ & $\mathbf{3 3 , 9 8}$ \\
\hline Cukup Baik & $32-<40$ & 15 & 28,30 \\
\hline Buruk & $24-<32$ & 11 & 20,75 \\
\hline Sangat & $<24$ & 2 & 3,77 \\
\hline Total & 53 & 100 \\
\hline
\end{tabular}

Sumber: Data Primer, 2017 (Diolah)

Berdasarkan Tabel 2 di atas dapat dikatakan bahwa Kualfikasi Hasil Seleksi di Grand Rocky Hotel Bukittinggi sebanyak $39,62 \%$ responden menyatakan baik, $37,73 \%$ responden menyatakan cukup baik, 20,75\% responden menyatakan sangat baik, dan 1,9\% responden menyatakan buruk.

3. Uji Persyaratan Analisis

a. Uji Normalitas

Tabel 3 menunjukkan bahwa nilai Asymp. Sig untuk variabel kualfikasi hasil seleksi adalah 0,604 dan untuk produktivitas kerja adalah 0,802. Dengan ini nilai > dari 0,05 , maka dapat dikatakan bahwa kedua data terdistribusi normal 


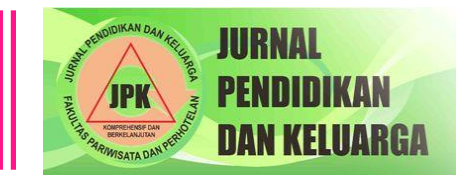

\section{b. Uji Homogenitas}

Tabel 4. Hasil Uji Homogenitas

\begin{tabular}{|c|c|c|c|}
\hline Levene Statistic & df1 & $\mathrm{df} 2$ & Sig. \\
\hline 1.694 & 9 & 31 & .133 \\
\hline
\end{tabular}

Berdasarkan hasil analisis uji homogenitas pada tabel diatas diperoleh nilai Sig adalah 0,133 dengan taraf signifikansi $>0,05$. Ini artinya nilai signifikansi data lebih besar dari taraf signifikansi, sehingga dapat diambil kesimpulan bahwa data berasal dari populasi yang mempunyai varian yang sama atau data bersifat homogen.

c. Uji Linearitas

Berdasarkan hasil analisis uji linearitas pada tabel diatas, diperoleh nilai Sig adalah 0,445dengan taraf signifikansi $>0,05$ yang artinya terdapat hubungan linear secara signifikan antara variabel hasil seleksi (X) dan produktivitas kerja (Y).
Tabel 5 . Hasil Uji Linearitas

\begin{tabular}{|c|c|c|c|c|c|c|c|}
\hline & & & $\begin{array}{r}\text { Sum of } \\
\text { Squares }\end{array}$ & Df & $\begin{array}{l}\text { Mean } \\
\text { Square }\end{array}$ & $\mathrm{F}$ & Sig. \\
\hline \multirow{2}{*}{\multicolumn{2}{|c|}{$\begin{array}{ll}\text { Y } & \text { Between } \\
* & \text { Groups }\end{array}$}} & (Combined) & 3615.552 & 21 & 172.169 & 3.593 & .001 \\
\hline & & \multirow{2}{*}{$\begin{array}{l}\text { Linearity } \\
\text { Deviation from } \\
\text { Linearity }\end{array}$} & 2613.217 & 1 & 2613.217 & 54.535 & .000 \\
\hline \multicolumn{2}{|l|}{$\mathrm{x}$} & & 1002.335 & 20 & 50.117 & 1.046 & .445 \\
\hline \multicolumn{3}{|c|}{ Within Groups } & 1485.467 & 31 & 47.918 & & \\
\hline \multicolumn{3}{|c|}{ Total } & 5101.019 & 52 & & & \\
\hline
\end{tabular}

\section{Uji Hipotesis}

Tabel 6.Hasil Uji R Square Variabel X Terhadap Y

\begin{tabular}{|c|c|c|c|c|}
\hline Model & $\mathrm{R}$ & R Square & $\begin{array}{c}\text { Adjusted R } \\
\text { Square }\end{array}$ & $\begin{array}{l}\text { Std. Error of } \\
\text { the Estimate }\end{array}$ \\
\hline 1 & $.716^{\mathrm{a}}$ & .512 & .503 & 6.984 \\
\hline \multicolumn{5}{|c|}{ a. $\quad$ Predictor Constant), $\mathrm{X}$} \\
\hline $\mathrm{KP}$ & \multicolumn{4}{|c|}{$=r^{2} \times 100 \%$} \\
\hline $\mathrm{KP}$ & \multicolumn{4}{|c|}{$=0,512 \times 100 \%$} \\
\hline
\end{tabular}

Berdasarkan tabel di atas diperoleh nilai $\mathrm{R}$ square 0,512 , artinya kontribusi variabel kualifikasi hasil seleksi terhadap produktivitas kerja karyawan adalah $51,2 \%, \quad$ sedangkan $\quad 48,8 \%$ dipengaruhi oleh faktor lain.
Tabel 3.Uji Normalitas

\begin{tabular}{|ll|l|l|}
\hline \multicolumn{2}{|r|}{ One-Sample Kolmogorov-Smimov Test } & $\mathrm{X}$ & $\mathrm{Y}$ \\
\hline $\mathrm{N}$ & & 53 & 53 \\
Normal Parameters ${ }^{\mathrm{a}}$ & Mean & 52.66 & 38.43 \\
& Std. & 6.662 & 9.904 \\
Most Extreme & Deviation & .105 & .088 \\
Differences & Absolute & .105 & .088 \\
& Positive & -.090 & -.075 \\
Kolmogorov-Smimov & .763 & .644 \\
Asymp. Sig. (2-tailed) & & .604 & .802 \\
\hline \multicolumn{2}{|r|}{ a. Test distribution is Normal. } \\
\hline
\end{tabular}

Berdasarkan tabel berikut diperoleh Nilai F hitung 53,571 dengan Sig. $0,000<0,05$, Artinya variabel kualifikasi hasil seleksi dapat menjelaskan variabel produktivitas kerja secara signifikan. 


\section{PEMBAHASAN}

Tabel 7. Signifikansi

\begin{tabular}{|l|r|r|r|c|c|}
\hline \multirow{2}{*}{ Model } & Sum of Squares & \multicolumn{1}{|c|}{ df } & Mean Square & F & Sig. \\
\hline \multirow{2}{*}{$\begin{array}{l}\text { Regression } \\
\text { Residual } \\
\text { Total }\end{array}$} & 2613.217 & 1 & 2613.21 & 53.571 & .000 \\
\cline { 2 - 6 } & 2487.802 & 51 & 48.780 & & \\
\cline { 2 - 7 } & 5101.019 & 52 & & & \\
\hline
\end{tabular}

a. Predictors: (Constant), $\mathrm{X}$

b. Dependent Variable: Y
Berdasarkan hasil penelitian yang dilakukan di Grand Rocky Hotel Bukittinggi, terlihat dari pengkategorian skor dan nilai rata- rata pada statistik data hasil penelitian tentang kualifikasi hasil seleksi di Grand Rocky Hotel Bukittinggi secara keseluruhan baik,

Tabel 8 Koefisisien Regresi Coefficients $^{\mathrm{a}}$

\begin{tabular}{|c|c|c|c|c|}
\hline & & \multicolumn{2}{|c|}{ Unstandardized Coefficients } & \multirow{2}{*}{$\begin{array}{c}\text { Standardized } \\
\text { Coefficients } \\
\text { Beta } \\
\end{array}$} \\
\hline & & B & Std. Error & \\
\hline & (Constant) & -17.602 & 7.716 & \\
\hline & & 1.064 & .145 & .716 \\
\hline
\end{tabular}

a. Dependent Variable: $\mathrm{Y}$

Dari tabel di atas didapat persamaan regresi sebagai berikut:

$\mathrm{Y}=\mathrm{a}+\mathrm{bX}=-17,602+1,064 \mathrm{X}$

Nilai konstanta sebesar $-17,602$ menunjukkan tanpa adanya pengaruh kualifikasi hasil seleksi nilai skala produktivitas kerja sebesar $-17,602$. Koefisien regresi sebesar 1,064 dengan nilai t hitung 7,319 pada sig. $0,000<0,05$. Artinya setiap peningkatan sebesar 1 satuan kualfikasi hasil seleksi akan meningkatkan 1,064 satuan produktivitas kerja. dengan presentase 39, $62 \%$. Walaupun secara termasuk dalam kategori baik, masih ąda signdikator keahlian dari variabel kûasllifákäsi hasil seleksi yang berada pada kảtêgợ cukup baik sebesar $35,84 \%$. Sehingga peningkatan dalam bidang ini harus dilakukan yaitu dengan cara pihak HRD harus lebih teliti dalam melakukan penerimaan karyawan. Keahlian calon karyawan harus diperhatikan karena hal ini akan sangat membantu karyawan dalam bekerja dan meningkatkan keberhasilan perusahaan.

Menurut Bangun (2012:159), "Seleksi adalah proses memilih calon karyawan yang memiliki kualifikasi sesuai dengan persyaratan pekerjaan, kegiatan seleksi dilakukan untuk mengurangi sebagian jumlah pelamar, sehingga diperoleh calon karyawan terbaik. Tanpa karyawan 


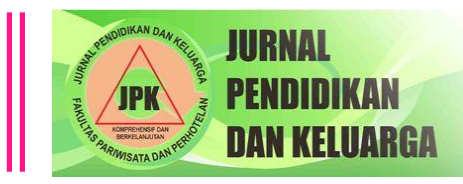

berkualitas sulit bagi perusahaan untuk mencapai keberhasilan"

Selanjutnya berdasarkan pengkategorian skor dan nilai rata-rata pada tatistic hasil penelitian tentang produktivitas kerja karyawan di Grand Rocky Hotel Bukittinggi secara keseluruhan di kategorikan baik dengan persentase $33,98 \%$. Walaupun secara keseluruhan dalam kategori baik, masih ada indikator kualitas kerja dari variable produktivitas kerja yang berada pada kategori cukup baik sebesar 28,30\%. Kualitas kerja karyawan harus ditingkatkan, pihak HRD harus mencari cara untuk meningkatkan kualitas kerja karyawan demi terciptanya hasil kerja yang sesuai dengan standar perusahaan. Menurut Anoraga (1992) dalam Yunarsih dan Suwatno (2011: 157) produktivitas kerja adalah "menunjukkan tingkat efisiensi proses menghasilkan dari sumber daya yang digunakan, yang berkualitas lebih baik dengan usaha yang sama.

Hasil uji hipotesis adalah nilai $\mathrm{F}$ hitung 53,571 dengan Sig. $0,000<0,05$, Artinya variabel kualifikasi hasil seleksi dapat menjelaskan variabel produktivitas kerja secara signifikan. $\mathrm{R}$ square 0,512 artinya kontribusi variabel hasil seleksi terhadap produktivitas kerja karyawan adalah $\quad 51,2 \%, \quad$ sedangkan $\quad 48,8 \%$ dipengaruhi oleh faktor lain. Nilai konstanta sebesar -17,602 menunjukkan bahwa tanpa adanya pengaruh hasil seleksi nilai skala produktivitas kerja sebesar -17,602. Koefisien regresi sebesar 1,064 dengan nilai t hitung 7,319 pada sig. $0,000<0,05$.

Artinya setiap peningkatan sebesar 1 satuan hasil seleksi akan meningkatkan 1,064 satuan produktivitas kerja. Maka Hipotesis yang diajukan adalah terdapat pengaruh yang signifikan antara Hasil Seleksi Terhadap Produktivitas Kerja Karyawan, maka $\mathrm{Ha}$ diterima. Karena faktor internal yang memepengaruhi produktivitas kerja adalah indikator kulifikasi hasil seleksi seperti yang diungkapkan Yunarsih dan Suwatno (2011:161) Faktor- faktor yang mempengaruhi produktivitas kerja adalah 1) Faktor internal: komitmen, struktur dan desain pekerjaan, lingkungan kerja, latar belakang pendidikan, pengalaman, minat, keahlian yang dikuasai komunikasi interpersonal. 2) Faktor Eksternal: kultur, lingkungan, umpan balik, dukungan kemitraan. 


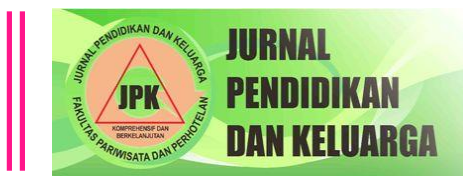

\section{KESIMPULAN DAN SARAN}

1. Kesimpulan

Secara keseluruhan kualifikasi hasil seleksi berada pada katergori baik sebesar $39,62 \%$, dan produktivitas kerja juga berada pada kategori baik sebesar 33,98\%. Berdasarkan hasil penelitian yang dilakukan, menunjukkan bahwa kualifikasi hasil seleksi mempengaruhi produktivitas kerja di Grand Rocky Hotel Bukittinggi sebesar 51,2 \% sedangakn 48,8 \% dipengaruhi oleh faktor lain seperti: disiplin kerja, motivasi dan hubungan antar individu.

2. Saran

Untuk menaggulangi indikator keahlian variabel kualifikasi hasil seleksi yang berada pada kategori cukup baik adalah dengan memberi persyaratan untuk calon karyawan agar melampirkan sertifikat pendukung untuk menunjang keahlian yang dimiliki. Pihak HRD juga harus cermat memilih karyawan pada saat interview berlangsung. Calon karayawan yang dipilih hendaknya memiliki keahlian yang dapat di percaya membantu pekerjaannya. Indikator kualitas kerja variabel produktivitas kerja juga berada pada kategori cukup baik sebesar $28,30 \%$ juga harus ditanggulangi caranya pihak HRD sebaiknya memberikan pelatihan rutin bagi karyawan. Hal ini bertujuan untuk membantu meninggkatkan kualitas kerja karyawan, contoh pelatihan yang diberikan misalnya karyawan housekeeping bisa diberikan pelatihan cara membersihkan kamar yang baik dan benar sesuai dengan SOP dan ketepatan waktu yang telah ditentukan.

\section{DAFTAR PUSTAKA}

Bangun. 2012. Manajemen Sumber Daya Manusia. Jakarta: Erlangga.

Bayu, Candra. 2012. Sumber Daya Manusia (Human Resources Management:http://chandrabayu.blog spot.com diakses tanggal 30 mei 2017.

Kristanu. 2013. Analisis Rekrutmen, Seleksi Dan Penempatan Karyawan Di PT.

Nyonya Meener Semarang. Surabaya: Universitas Kristen Petra.

Marnis. 2008. Manajemen Sumber Daya Manusia. Sidoarjo: Zifatama Publisher.

Simamora. 2004. Manajemen Sumber Daya Manusia. Yogyakarta: STIE YPKN

Yunarsih, Suwatno. (2011), Manajemen Sumber Daya Manusia. Bandung: CV Alfbeta . 